\title{
Absence deformity of leg-cataract syndrome
}

INSERM

\section{Source}

INSERM. (1999). Orphanet: an online rare disease and orphan drug data base. Absence deformity of leg-cataract syndrome. ORPHA:2310

Absence deformity of leg cataract is a very rare syndromic limb malformation described in two distantly related boys. It is characterized by absence deformity of the left leg, progressive scoliosis, short stature, congenital cataract associated with dysplasia of the optic nerve. No intellectual deficit has been observed. 